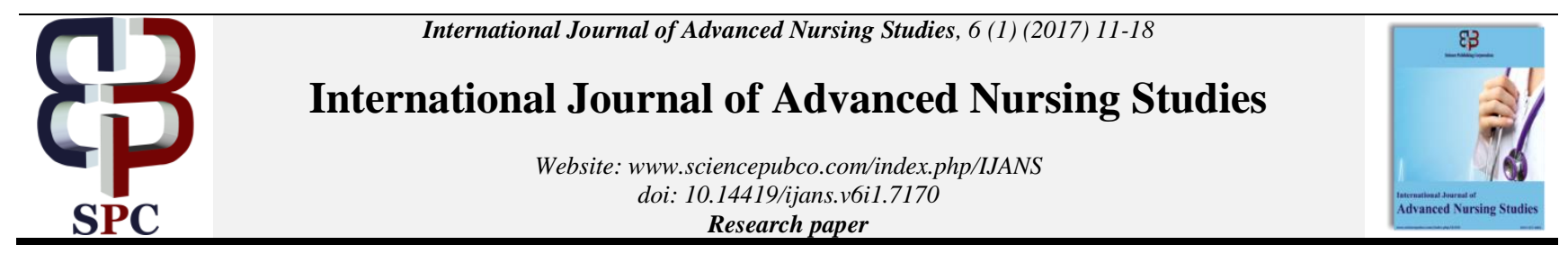

\title{
The risk factors and outcome of early identified acute kidney injury among critically ill obstetric patients
}

\author{
Amal Ismael Abd El-Hafez ${ }^{1 *}$, Asmaa Aly Mahgoup ${ }^{1}$, Eman R. Ahmad ${ }^{2 *}$ \\ ${ }^{1}$ Critical Care Nursing Department, Faculty of Nursing, Assiut University, Assiut, Egypt \\ ${ }^{2}$ Obstetrics and Gynecological Nursing Department, Faculty of Nursing, Assiut University, Assiut, Egypt \\ *Corresponding authorE-mail: dramalcritical@aun.edu.eg,emomedo2@yahoo.com
}

\begin{abstract}
Background: Acute kidney injury (AKI) is one of the most challenging and serious complications of pregnancy and postpartum period that facing critical care nurses in Intensive Care Unit (ICU). Having a uniform standard for identifying and classifying AKI would enhance critical care nurses' ability to recognize these patients and leading to better outcomes.

Objective: This work aimed to explore the risk factors and outcome of early identified acute kidney injury of critically obstetric patients in Obstetric ICU. Design. A descriptive cross sectional research design was used in this study. Participants: A total sample of 338 women admitted to Obstetric ICU at Woman Health Hospital, Assiut City, Egypt. Method: Three tools were used.Tool I was developed by the researcher and included demographic and obstetric history, lab parameters, complications and outcomes arising from AKI. The Sequential Organ Failure Assessment (SOFA) score as tool II to determine the extent of a patient's organ function or rate of failure. Measurement of serum creatinine and urine output were used to early identify AKI stages according to Acute Kidney Injury Network (AKIN) Criteria (tool III). Results: The prevalence of AKI among obstetric patients admitted to obstetric ICU was $10.1 \%$; of them 52.9\% needed renal replacement therapy and the mortality rate was $29.4 \%$. Postpartum hemorrhage was the most common cause of AKI and its prevalence was $41.2 \%$. It was also found that $74.5 \%$ of AKI patients developed complications. Conclusion: AKI complicated $10.1 \%$ of total admitted women to the OICU in the studied period. Postpartum hemorrhage represents the most prevalent risk factors with a highly significant SOFA score compared to other risk factors as sever preeclampsia, eclampsia, HEELP \& APH with acute fatty liver.
\end{abstract}

Keywords: Early Identified AKI Outcomes; Intensive Care Unit; Obstetric Complications.

\section{Introduction}

Acute Kidney Injury (AKI) is associated with an increased morbidity and mortality regardless of the underlying cause, and whenever AKI develops in pregnancy, it denotes a serious complication. It was reported that critically ill obstetric patients represent an interesting group with sole characteristics, as the presence of a fetus represents a challenge in their management in addition to altered maternal physiology, and diseases specific to pregnancy [1] Pregnant patients account for a small number of ICU admissions in developed countries $\left(<\_2 \%\right)$, but they can reach up to $10 \%$ or more in developing countries [1]. It has different etiologies and can be multifactorial as more than one etiology of AKI can get along with in the same patient, for example postpartum haemorrhage and use of non-steroidal anti-inflammatory drugs (NSAIDs). [2, 3]

In 2007, "the Acute Kidney Injury Network (AKIN) developed a modified standard for diagnosing and classifying acute kidney injury (AKI"). This classification system is a modification of the previously described risk, injury, failure, loss, and end-stage (RIFLE) criteria. Among other modifications, the AKIN staging requires an absolute serum creatinine change of $0.3 \mathrm{mg} / \mathrm{dl}$ in a 48 hour period to establish the diagnosis of AKI. [4] During the past 50 years, extensive declines in obstetric acute renal failure occurred in high income countries, referred to improvement in obstetric care and to the legalization of pregnancy terminations and an associated decrease in infections. [5-7] However, it is still common during pregnancy in developing countries and being responsible for a high maternal morbidity and mortality rate. In the same line, Susan et al [8] reported that "in spite of the significant reduction of incidence of acute kidney injury in pregnancy over the second half of the 20th century, it is still associated with major maternal and perinatal morbidity and mortality"

A set of systemic and renal physiological adaptive mechanisms occur during a normal gestation clarifies the possibility of acquiring acute kidney injury that will oblige several changes in laboratory parameters of renal function, electrolytes, fluid and acid-base balances. Susan et al [8]. These changes are presented in the increase in kidney size by about $1-1.5 \mathrm{~cm}$ due to renal vascular and interstitial space volume expansion that lead to over $90 \%$ of pregnant women develop a physiological hydronephrosis of pregnancy [9]. These anatomical changes may be present until the 16th postpartum week and indorses urinary stasis in the ureters, leading to the development of urinary tract infections. [10] As most of the main organs are affected by AKI, critical care nurses must be able to assess how the disease affects the patient holistically [11].

In developing countries, acute kidney injury in pregnancy represents severe health problem. It affects $10 \%-20 \%$ of hospitalized adults and is associated with an increased risk of chronic kidney disease and further complications [12] The severity and duration of AKI determines outcomes, including dialysis requirement, renal functional recovery and survival. [13] In Egypt, Siam et al [14] found that AKI occurred in 88 cases (12.39\%) of obstetric patients admitted to Intensive Care Unit of Zagazig University Hospitals from January 2007 to December 2010. These increases are of 
concern because obstetric acute renal failure is associated with high rates of maternal morbidity and a case fatality rate of $2.9 \%$. Major risk factors for obstetric acute renal failure include chronic hypertensive disease, pre-eclampsia, postpartum haemorrhage, antepartum haemorrhage, sepsis, and other infections. [15] Turney et al [16] \& Gurrieri et al. [17] \& Bateman et al, [18] Moreover, et al, [19] and Andrew et al, [20] reported that " prevention of AKI is principal, it can occur in both hospital and community settings", that emphasize the importance of identifying patients at risk of AKI and the need for collaboration among all those involved in the care of these patients as critical care nurse and maternity nurses who should be cautious and be able to identify individuals who are at greater risk of developing AKI. For that our study was conducted to early identify the AKI, highlight the risk factors to it and explore the outcomes among critically ill obstetric patients.

\section{Subjects and method}

\subsection{Research design}

A descriptive cross sectional research design was used in this study.

\subsection{Setting}

The study was conducted in Obstetric ICU at Woman Health Hospital/Assiut University Hospital. Assiut City, Egypt. This hospital was chosen, as it is a governmental, tertiary level care hospital and the first specialized center in Upper Egypt with high turnover of parturient.

\subsection{Study subjects}

A total of 338 of critically ill obstetric peripartum patients admitted to obstetric ICU from July 2015 to January 2016 were included in the study sample.

\subsubsection{Inclusion criteria}

All the pregnant or postpartum patients who were admitted to the Obstetric ICU during the study period.

\subsubsection{Exclusion criteria}

Excluded from the current study those who had a history of kidney disease or surgery, history of hypertension and diabetes before pregnancy, and who were under renal replacement therapy.

\subsection{Tools}

Three tools were used to collect data related to the study.

\subsubsection{Tool I}

Acute kidney injury assessment tool. This tool was developed by the researcher after reviewing the relevant literatures and used to early identify pregnancy associated AKI, lab parameters, complications and outcomes arising from pregnancy associated AKI. It comprises four parts

Part one: Patients' characteristics. It includes woman age, past medical history, and ICU stay, reproductive data as parity, gestational age, and current obstetric diagnosis.

Part two: laboratory investigations namely creatinine, urea, electrolytes, liver function test and blood gases.

Part three: patient's outcome as recovered by medical management or received renal replacement therapy or regressed to chronic renal failure, ICU survival as died or survived.

Part four: AKI complications: namely acidosis, hyperkalemia, pulmonary edema and loss of consciousness.

\subsubsection{Tool II}

Sequential Organ Failure Assessment (SOFA) scale. It has been developed by European Society of Critical Care Medicine (ESCCM), in 1994, as a system for measuring the status of critically ill patient. The SOFA score is a tool used to determine the extent of a patient's organ function or rate of failure. The score is based on six different scores, one each for the respiratory, cardiovascular, coagulation, and hepatic, renal and neurological systems. Both the mean and highest SOFA scores are predictors of patients' outcome. An increase in SOFA score during the first 24 to 48 hours in the ICU predicts a mortality rate of at least $50 \%$ up to $95 \%$. Scores less than 9 give predictive mortality at $33 \%$ while above 11 can be close to or above 95\%. [21]

\subsubsection{Tool III}

Acute Kidney Injury Network (AKIN) Criteria. It includes three stages to identify the stage of acute renal failure. The AKIN classification was published in March 2007 in Critical Care. [22]

\begin{tabular}{|c|c|c|}
\hline $\begin{array}{l}\text { AKIN } \\
\text { stage }\end{array}$ & Serum creatinine criteria & $\begin{array}{l}\text { Urine output } \\
\text { criteria }\end{array}$ \\
\hline 1 & $\begin{array}{l}\text { Serum creatinine increase } \geq 26.5 \mu \mathrm{mol} / 1 \\
(\geq 0.3 \mathrm{mg} / \mathrm{dl}) \text { OR increase to } 1.5-2.0 \text {-fold } \\
\text { from baseline }\end{array}$ & $\begin{array}{l}<0.5 \mathrm{ml} / \mathrm{kg} / \mathrm{h} \text { for } \\
6 \mathrm{~h}\end{array}$ \\
\hline 2 & $\begin{array}{l}\text { Serum creatinine increase }>2.0-3.0 \text {-fold } \\
\text { from baseline. }\end{array}$ & $\begin{array}{l}<0.5 \mathrm{ml} / \mathrm{kg} / \mathrm{h} \text { for } \\
12 \mathrm{~h}\end{array}$ \\
\hline 3 & $\begin{array}{l}\text { Serum creatinine increase }>3.0 \text {-fold from } \\
\text { baseline OR serum creatinine } \geq 354 \mu \mathrm{mol} / 1 \\
(\geq 4.0 \mathrm{mg} / \mathrm{dl}) \text { with an acute increase of at } \\
\text { least } 44 \mu \mathrm{mol} / 1(0.5 \mathrm{mg} / \mathrm{dl}) \text { OR need for } \\
\text { renal replacement therapy (RRT). }\end{array}$ & $\begin{array}{l}<0.3 \mathrm{ml} / \mathrm{kg} / \mathrm{h} \text { for } \\
24 \mathrm{~h} \mathrm{OR} \text { anuria } \\
\text { for } 12 \mathrm{~h} \mathrm{OR} \\
\text { need for RRT }\end{array}$ \\
\hline
\end{tabular}

\subsection{Method}

- $\quad$ Research proposal was approved from Ethical Committee in the Faculty of Nursing-Assiut University, Egypt. An official permission to conduct the study was obtained from the director of Obstetric Intensive Care Unit (OICUs) at Woman Health Center- Assiut University Hospital to collect data from critically ill obstetric patients admitted to (OICUs).

- Written informed consent was obtained from each patient or from the responsible person for the unconscious patients after explaining the aim and nature of the study. The investigators emphasized that the participation is maintaining confidentiality and anonymity of the patients will be assured through data coding. Patients were assured that they can withdraw from the study at any time without any rational.

- A pilot study was done on $10 \%$ of the sample (34 patients) to test the clarity of the tools and to estimate the time needed to fill the sheet. The necessary modifications were done (observational data about patients' vital signs were omitted as it has no significant importance related to AKI in pregnancy). The pilot sample was excluded from the study.

- The tools were tested for content related validity by jury of 3 specialists in the field of critical care nursing, obstetrics \& Gynaecological nursing and anesthetic medicine from Assiut University and the necessary modifications were done. The Content Validity Index (CVI) of .80 was conducted. Cronbach's Alpha revealed high reliability for tool (I) which was 0.822 . While, reliability and validity of tool II \& III were determined previously.

- Other determinants of acute kidney injury examined in the study were maternal age and parity, multi-fetal gestation, caesarean delivery, and induction of labour. Maternal morbidity examined included diabetes (pre-existing or gestational), oedema and proteinuria during pregnancy without hypertension, sepsis, other puerperal infection, placenta praevia, placental abruption, and unspecified antepartum haemorrhage used tool I.

- All critically ill patients who were admitted to OICU during the study time had been assessed using Sequential Organ 
Failure Assessment (SOFA) score (tool II) during the first 24 hours to determine the extent of a patient's organ function/failure and predict the mortality rate.

- All critically ill obstetric patients were also assessed daily using AKIN criteria checklist (tool III) to early identify the acute kidney injury and categorize every case to the defined stage of AKI.

- Every patient who identified with any stage of AKI was monitored daily using tool I and tool III. Evaluated to identify their outcome and complications until discharge from OICU.

- All cases were reported to the ICU physician and referred to nephrologists' examination and the relevant investigations were done. All patients were received their medical therapy and renal replacement therapy if needed.

- An exploration of the factors associated with AKI was done and every patient with acute kidney injury was evaluated to identify their outcome and complications until discharge from OICU used tool I.

\section{Statistical analysis}

- The data were tested for normality using the AndersonDarling test and for homogeneity variances prior to further statistical analysis. Categorical variables were described by number and percent $(\mathrm{N}, \%)$, where continuous variables described by mean and standard deviation (Mean, SD). Chisquare and fisher exact tests used to compare between categorical variables where compare between continuous variables by unpaired t-test and ANOVA (parametric tests) for normally distributed variables. Relative risk and 95\% CI of relative risk to assess the relative risk variables of renal outcome and AKI Complications. A two-tailed $p<0.05$ was considered statistically significant. All analyses were performed with the IBM SPSS 20.0 software and MedCalc 14.

\section{Results}

Our study was conducted on 338 pregnant and postnatal patients who were admitted at Obstetric ICU from July 2015 to January 2016. In this study, the mean age of patients were $28+6.9$ years old and mean ICU duration was $15.1+10.8$ days. Two thirds of them were multigravida. As regards their distribution according to antepartum \& postpartum, $43.2 \%$ and $56.8 \%$ respectively and the vast minority of the sample had past medical/surgical history or previous obstetric complications $(6.2 \% \& 5.1 \%$ respectively). In relation to SOFA score, it was found that $51.5 \%$ of studied sample were scored between $10-15$ score. (Table 1). Of the studied sample $34(10.1 \%)$ out of 338 pregnant and postnatal patients were met AKIN criteria and $41.2 \%$ of studied sample had postpartum hemorrhage as a cause for acute kidney injury followed by HELLP syndrome, severe preeclampsia \& eclampsia and APH \& acute fatty liver $(35.3 \%, 14.7 \& 8.8 \%$ respectively) Figure (1).

Concerning the stages of identified acute kidney injury of critically obstetric patients, figure 2 illustrates that $29 \%, 53 \%$ and $18 \%$ were categorized as stages 1,2 and 3 respectively.

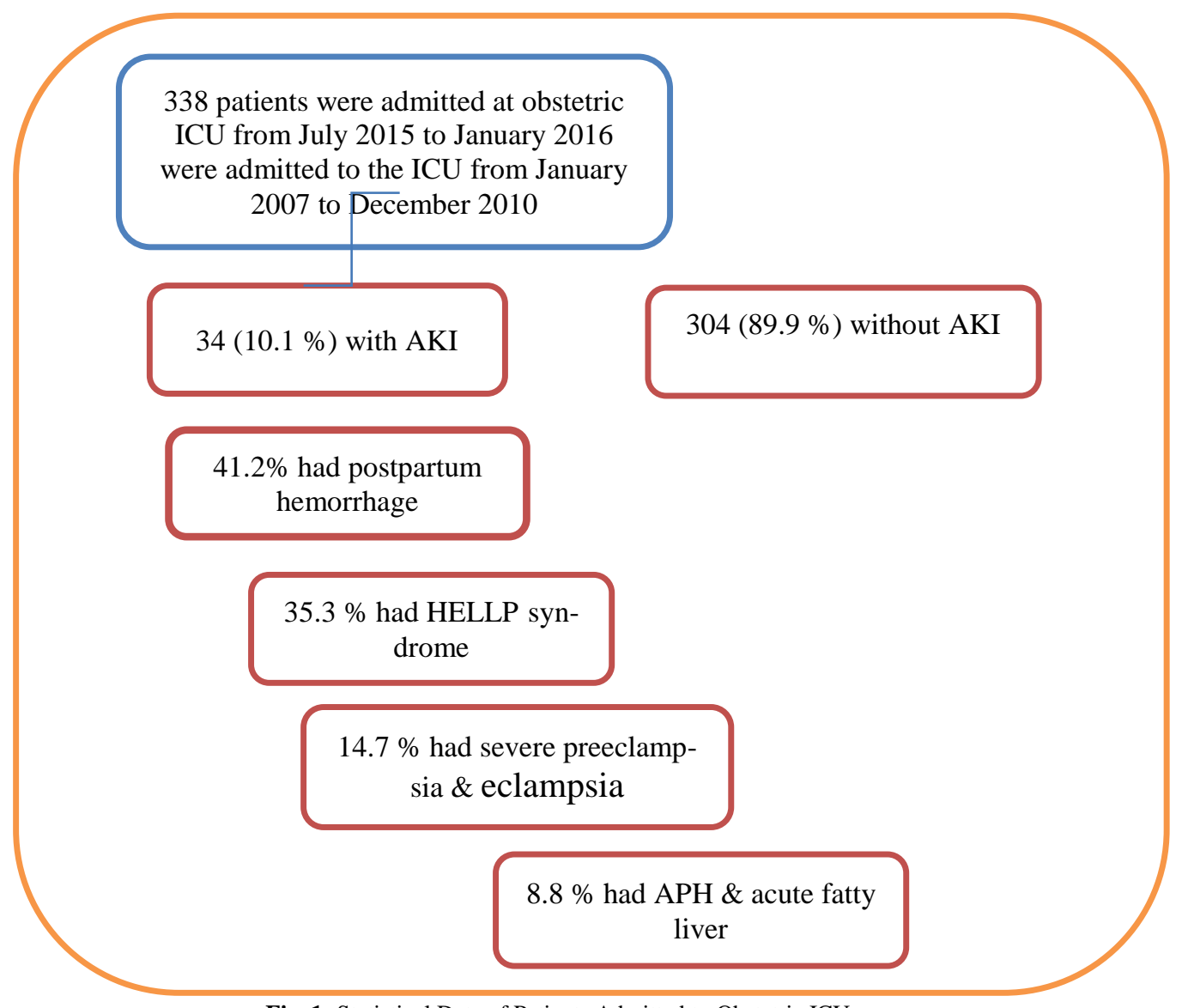

Fig. 1: Statistical Data of Patients Admitted to Obstetric ICU.

This hospital is the first specialized center in Upper Egypt

Table 2 presents that $70.6 \%, 52.9 \%$, and $73.5 \%$ of patients had survived, needed renal replacement therapy, and developed AKI complications respectively.

Regarding the different types of developed AKI complications, Figure 3 show that, acidosis was more prevalent among $52.9 \%$ of patients. The least AKI complication was the hyperkalemia (12.5 $\%)$.

Table 3 shows that statistical significant differences were found between ICU survival and patients' characteristic, indicating that most of died patients had high SOFA score and diagnosed with postpartum hemorrhage. It was also found statistical significant 
differences between renal outcomes and patients' characteristic, indicating that higher percentage of renal recovered patients were pregnant with SOFA score (10 -15), and higher percentage of patients who had postpartum hemorrhage needed RRT.

Among those who had complications related early identified acute kidney injury (25 cases), it is clear that a significant difference was apparent regards mean patients' age and ICU stay, however concerning parity this table shows that acute kidney injury was more prevalent among those who are multigravida and no significant difference was apparent when comparing antepartum to postpartum cases. Table (4)

Table 5 portrays a statistical significant difference was found between risk factor of acute kidney injury and SOFA score indicating that higher percentage of SOFA score (16 and more) was found among patients diagnosed with postpartum hemorrhage.
That indicating postpartum hemorrhage considered as the most prevalent risk factor for acute kidney injury

On multivariate analysis, we calculated the risk of different clinical characteristics and renal outcome of AKI and it was found statistical significant differences indicating that the postpartum cases especially those who had postpartum hemorrhage increases the risk of renal replacement therapy (dialysis), however, the antepartum and HEELP syndrome cases had more chance for renal recovery with medical management (Table 6).

Table 7 shows statistical significant differences indicating that higher SOFA score (10+), and postpartum hemorrhage increases the risk of AKI complications ( $\mathrm{p}=0.033$ and 0.008 respectively). On the contrary, preeclampsia/ Eclampsia didn't increase risk of AKI complications $(\mathrm{p}=0.019)$.

Table 1: General Characteristics \& Reproductive History of the Studied Sample (N=338)

\begin{tabular}{lll}
\hline Characteristics & $\mathrm{N}$ & $\%$ \\
\hline Age Range (Mean+SD) & $20-45(28+6.9)$ & \\
ICU stay Range (Mean+SD) & $2-43(15.1+10.8)$ & \\
Gestational age & & 94.9 \\
Range (Mean+SD) & $21-36(29.4+4.4)$ & 5.1 \\
Previous obstetric complications & 321 & 39.1 \\
No & 17 & 60.9 \\
Yes & & 43.2 \\
Pumber of pregnancies (gravidity) & 132 & 56.8 \\
Multigravida & 206 & 93.8 \\
Obstetric cases & & 6.2 \\
Antepartum cases & 146 & \\
Postpartum cases & 192 & 42.3 \\
No & & 45.9 \\
Yes & & \\
SOFA score (At 48hr) & 317 & 11.8 \\
$0-9$ & 21 & 143 \\
$10-15$ & 155 & 40 \\
16 and more
\end{tabular}

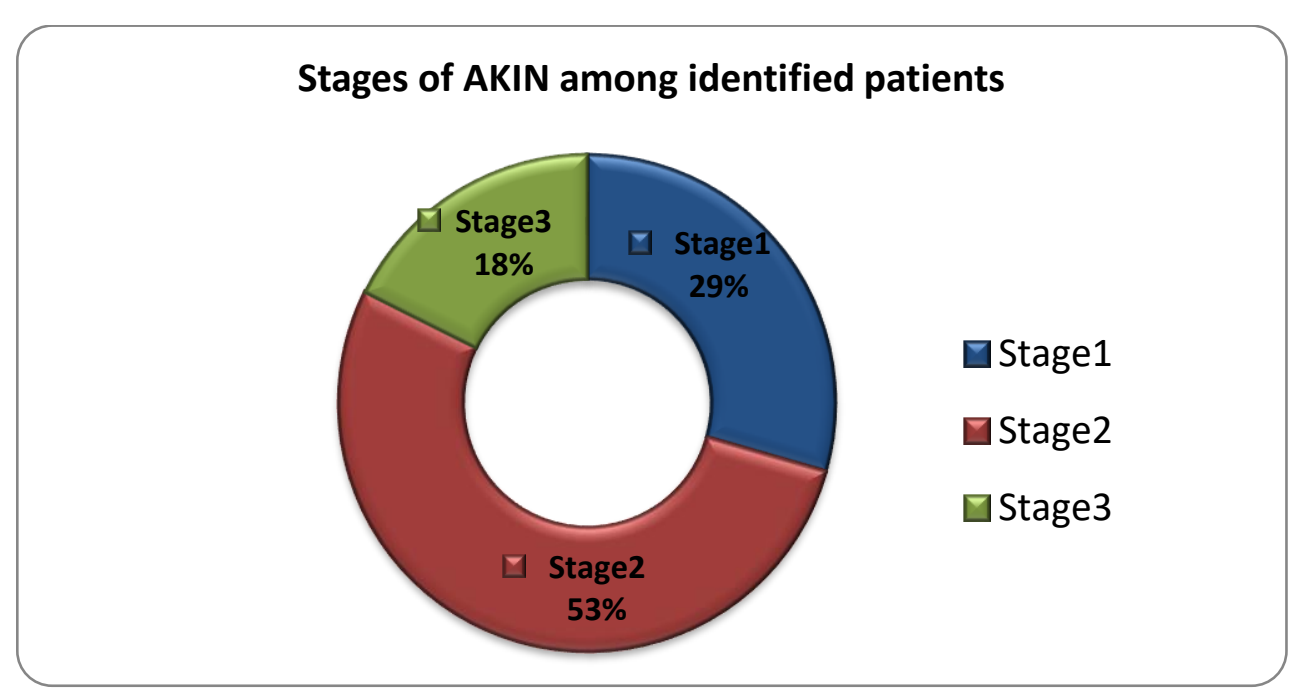

Fig. 2: Stages of Acute Kidney Injury Network Among Identified Obstetric Acute Kidney Injury (N=34).

Table 2: ICU Survival, Renal Outcomes and Complications of Obstetric Acute Kidney Injury (N=34)

\begin{tabular}{lc}
\hline & $\mathrm{N}$ \\
\hline ICU survival & \\
Died & \\
Survived & 29.4 \\
Renal outcome & 70.6 \\
Renal replacement therapy (dialysis) & 52.9 \\
Recovered by medical management & 47.1 \\
Chronic renal dialysis & 0.00 \\
AKI complications & 18 \\
developed complications & 0 \\
no complications & 73.5 \\
\hline
\end{tabular}




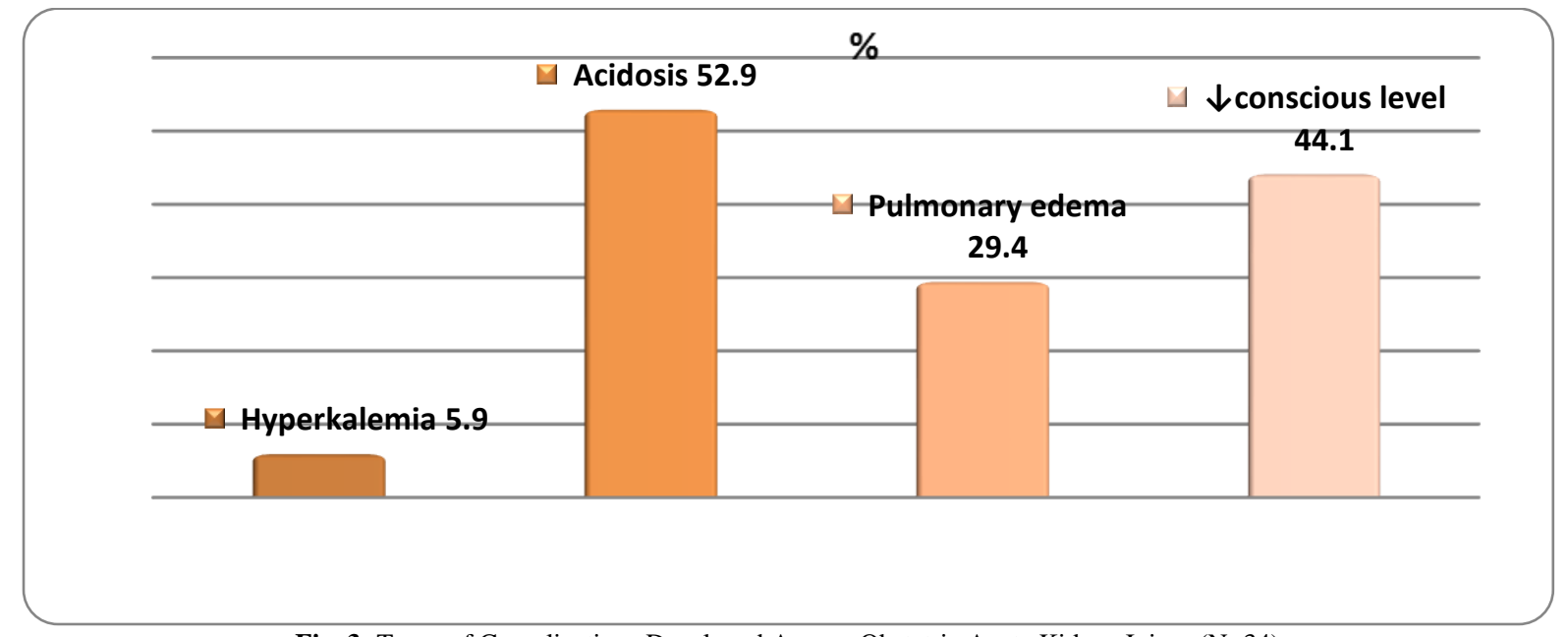

Fig. 3: Types of Complications Developed Among Obstetric Acute Kidney Injury (N=34).

Table 3: ICU Survival and Renal Outcomes in Relation to Clinical Profile of Obstetric Acute Kidney Injury $(\mathrm{N}=34)$

\begin{tabular}{|c|c|c|c|c|c|c|}
\hline 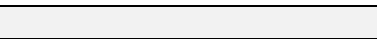 & ICU survival & & & Renal outc & & \\
\hline & died & survived & P. value & RRT & recovered & P. value \\
\hline Age & $25.7 \pm 5.2$ & $29 \pm 7.3$ & 0.211 & $28.7 \pm 8.2$ & $27.2 \pm 5$ & 0.523 \\
\hline ICU stay & $17.8 \pm 18.3$ & $13.9 \pm 5.7$ & 0.348 & $15.8 \pm 13.8$ & $14.2 \pm 6.4$ & 0.665 \\
\hline Antepartum & $3(30 \%)$ & $14(58.3 \%)$ & \multirow{2}{*}{0.123} & $5(27.8 \%)$ & $12(75 \%)$ & \multirow{2}{*}{$0.006^{* *}$} \\
\hline Postpartum & $7(70 \%)$ & $10(41.7 \%)$ & & $13(72.2 \%)$ & $4(25 \%)$ & \\
\hline \multicolumn{7}{|l|}{ SOFA score } \\
\hline $0-9$ & $1(10 \%)$ & $7(29.2 \%)$ & \multirow{3}{*}{$0.016^{*}$} & $2(11.1 \%)$ & $6(37.5 \%)$ & \multirow{3}{*}{$0.002 * *$} \\
\hline $10-15$ & $3(30 \%)$ & $14(58.3 \%)$ & & $7(38.9 \%)$ & $10(62.5 \%)$ & \\
\hline 16 and more & $6(60 \%)$ & $3(12.5 \%)$ & & $9(50 \%)$ & $0(0 \%)$ & \\
\hline \multicolumn{7}{|l|}{ Risk factors } \\
\hline Postpartum hemorrhage $(n=14)$ & $7(70 \%)$ & $7(29.2 \%)$ & \multirow{5}{*}{$0.018 *$} & $14(77.8 \%)$ & $0(0 \%)$ & \multirow{5}{*}{$<0.001 * *$} \\
\hline Preeclampsia, Eclampsia $(n=5)$ & $1(10 \%)$ & $4(16.7 \%)$ & & $0(0 \%)$ & $5(31.3 \%)$ & \\
\hline $\operatorname{HEELP}(n=12)$ & $0(0 \%)$ & $12(50 \%)$ & & $1(5.6 \%)$ & $11(68.8 \%)$ & \\
\hline \multirow[t]{2}{*}{ APH with acute fatty liver $(n=3)$} & $2(20 \%)$ & $1(4.2 \%)$ & & $3(16.7 \%)$ & $0(0 \%)$ & \\
\hline & $100 \%$ & $100 \%$ & & $100 \%$ & $100 \%$ & \\
\hline
\end{tabular}

Table 4: Relationship between Characteristics and Complications Arising from Acute Kidney Injury $(\mathrm{N}=34)$

\begin{tabular}{|c|c|c|c|c|c|c|}
\hline \multirow[b]{2}{*}{ Characteristics } & \multirow[b]{2}{*}{$\begin{array}{l}\text { No complications } \\
(\mathrm{n}=9)\end{array}$} & \multicolumn{4}{|c|}{ Complications $(n=25)$} & \multirow[b]{2}{*}{ P. value } \\
\hline & & $\begin{array}{l}\text { hyperkalemia } \\
(\mathrm{n}=2)\end{array}$ & $\begin{array}{l}\text { acidosis } \\
(\mathrm{n}=18)\end{array}$ & $\begin{array}{l}\text { pulmonary } \\
\text { edema } \\
(\mathrm{n}=10)\end{array}$ & $\begin{array}{l}\downarrow \text { conscious level } \\
(\mathrm{n}=15)\end{array}$ & \\
\hline ICU stay & $15.3 \pm 8.1$ & $9 \pm 0$ & $17.5 \pm 12.9$ & $21.5 \pm 15.1$ & $15.1 \pm 14.9$ & $0.038 *$ \\
\hline Antepartum cases & $6(66.7 \%)$ & $2(100 \%)$ & $8(44.4 \%)$ & $5(50 \%)$ & $5(33.3 \%)$ & \\
\hline Postpartum cases & $3(33.3 \%)$ & $0(0 \%)$ & $10(55.6 \%)$ & $5(50 \%)$ & $10(66.7 \%)$ & 0.306 \\
\hline \multicolumn{7}{|l|}{ SOFA score } \\
\hline $0-9$ & $6(66.7 \%)$ & $0(0 \%)$ & $2(11.1 \%)$ & $0(0 \%)$ & $0(0 \%)$ & \multirow{3}{*}{$<0.001 * *$} \\
\hline $10-15$ & $3(33.3 \%)$ & $0(0 \%)$ & $9(50 \%)$ & $8(80 \%)$ & $6(40 \%)$ & \\
\hline 16 and more & $0(0 \%)$ & $2(100 \%)$ & $7(38.9 \%)$ & $2(20 \%)$ & $9(60 \%)$ & \\
\hline \multicolumn{7}{|l|}{ Risk factors } \\
\hline Postpartum hemorrhage & $0(0 \%)$ & $2(100 \%)$ & $12(66.7 \%)$ & $5(50 \%)$ & $10(66.7 \%)$ & \multirow{4}{*}{$<0.001 * *$} \\
\hline $\begin{array}{l}\text { Preeclampsia , Eclamp- } \\
\text { sia }\end{array}$ & $5(55.6 \%)$ & $0(0 \%)$ & $0(0 \%)$ & $0(0 \%)$ & $0(0 \%)$ & \\
\hline HEELP & $4(44.4 \%)$ & $0(0 \%)$ & $3(16.7 \%)$ & $5(50 \%)$ & $3(20 \%)$ & \\
\hline APH \& Acute fatty liver & $0(0 \%)$ & $0(0 \%)$ & $3(16.7 \%)$ & $0(0 \%)$ & $2(13.3 \%)$ & \\
\hline
\end{tabular}

Table 5: Relationship between Risk Factors of Obstetric Acute Kidney Injury and SOFA Score

\begin{tabular}{llllll}
\multicolumn{1}{c}{ Table 5: Relationship between Risk Factors of Obstetric Acute Kidney Injury and SOFA Score } \\
\hline
\end{tabular}

\footnotetext{
*p-value
} 
Table 6: Relative Risk Factors Associated with Renal Outcomes

\begin{tabular}{|c|c|c|c|c|c|c|}
\hline & \multicolumn{2}{|c|}{ Renal outcomes } & RR & \multicolumn{2}{|c|}{$95 \% \mathrm{CI}$ of RR } & P. value \\
\hline Age $(>30)$ & 4 & 5 & 1.11 & 0.36 & 3.44 & 0.855 \\
\hline ICU stay (>14 days) & 6 & 6 & 0.89 & 0.34 & 2.21 & 0.799 \\
\hline Antepartum cases & 12 & 5 & 0.37 & 0.17 & 0.82 & $0.015^{*}$ \\
\hline Postpartum hemorrhage & 0 & 14 & 25.9 & 1.67 & 402.7 & $0.020 *$ \\
\hline Preeclampsia, Eclampsia & 5 & 0 & 0.08 & 0.01 & 1.36 & 0.081 \\
\hline HEELP Syndrome & 11 & 1 & 0.08 & 0.01 & 0.56 & $0.011 *$ \\
\hline APH & 0 & 3 & 6.26 & 0.35 & 112.7 & 0.213 \\
\hline
\end{tabular}

Table 7: Relative Risk Factors Associated with AKI Complications

\begin{tabular}{|c|c|c|c|c|c|c|}
\hline & \multicolumn{2}{|c|}{ AKI Complications } & \multirow{2}{*}{ RR } & \multicolumn{2}{|c|}{$95 \%$ CI of RR } & \multirow{2}{*}{ P. value } \\
\hline & No & Yes & & Lower & Upper & \\
\hline Age $(>30)$ & 1 & 8 & 2.9 & 0.42 & 19.93 & 0.284 \\
\hline ICU stay ( >14 days) & 3 & 9 & 1.1 & 0.37 & 3.12 & 0.887 \\
\hline SOFA score $(10+)$ & 3 & 23 & 2.8 & 1.09 & 7 & $0.033^{*}$ \\
\hline Antepartum cases & 6 & 11 & 0.66 & 0.35 & 1.25 & 0.203 \\
\hline Postpartum hemorrhage & 0 & 14 & 11.2 & 0.73 & 169.8 & $0.008 * *$ \\
\hline Preeclampsia, Eclampsia & 5 & 0 & 0.03 & 0.01 & 0.58 & $0.019^{*}$ \\
\hline HEELP & 4 & 8 & 0.72 & 0.28 & 1.82 & 0.487 \\
\hline $\mathrm{APH}$ & 0 & 3 & 2.7 & 0.15 & 47.6 & 0.499 \\
\hline
\end{tabular}

\section{Discussion}

Acute kidney injury (AKI) is one of the most challenging and serious complications of pregnancy and postpartum period.[23], which may reflects the limited prenatal care and early detection of high-risk pregnancies which foster reports on critical care and view them with respect to maternity services. It is therefore vital that nurses understand what acute kidney injury is, and the management of it in order to deliver holistic care to the patient concerned and monitors for AKI complications [24].

Our study aimed to explore the outcomes of early identified obstetric acute kidney injury at obstetric ICU. The reported incidence of obstetric AKI in the developed countries is $1-2.8 \%$, while in developing countries it is $9-25 \%$. [23] In the same line, Prakash et al, [25] \& Goplani et al, [26] emphasized that the incidence of pregnancy related AKI still accounts for 5-20\% in developing countries despite a decrease in renal cortical necrosis following obstetrical complication. Moreover, several studies show the incidence of this syndrome has increased over the decades, being associated with a longer life expectancy and multiple comorbidities in the population. [27]

However, our work revealed that the prevalence of AKI was found to be $10.1 \%$ among critically ill obstetric patients admitted to OICU during the study period. The reason for this decrease in incidence is due to the exclusion of those who had a history of kidney disease or surgery, history of hypertension and diabetes before pregnancy as the vast minority of the sample had past medical / surgical history or previous obstetric complications $(6.2 \%$, $5.1 \%$ respectively), and no cases were under renal replacement therapy. Furthermore this finding was supported by Godara et al, [28] who reported that the prevention of pregnancy-related complications such as septic abortion, early and more effective treatment of pre-eclampsia and performing selective timely lower segment cesarean section may be responsible about this prevalence.

Concerning the stages of early identified acute kidney injury, the present study, illustrated that $29 \%, 53 \%$ and $18 \%$ were categorized as stages 1, 2 and 3 respectively which indicated that stage 2 AKI according to AKIN criteria was more prevalent among our study. This difference may be related to different patient characteristics, limited number of co-morbid conditions and the criteria used to define and stratify AKI. However, Mandelbaum et al, [29] who studied the outcome of critically ill patients with acute kidney injury using the Acute Kidney Injury Network criteria found that in-hospital mortality rates were: $13.9 \%, 16.4 \%$, and $33.8 \%$ for AKI of stages 1, 2 and 3, respectively. Also, Ostermann and Chang 2008) [27] found that AKI III was an independent risk factor for ICU mortality. Moreover, Ashraf et al, [30] who studied clinical characteristics and outcome of acute kidney injury in in- tensive care units in 749 Egyptian patients found that $(21.2 \%)$ of them met AKIN criteria, 26.3\% classified as stage 1,20.2\% classified as stage $2,53.5 \%$ classified as stage 3 .

As regards the general characteristics of the studied sample, the mean age of patients was $28+6.9$ years old this goes with the study of Arrayhani et al. [31] who reported that the mean age was in an average of $29.03 \pm 6.3$ years old. Other studies backing up our findings regarding mean age are study of Khalil et al. [32] which reported average age is 29 years old, However, the study done by Arora et al [33] found that the subjects' age appeared to be a factor significantly associated with unfavorable evolution ( $\mathrm{p}$-value $<0.001)$. In the literature, this factor was associated with increase perinatal complications, including premature delivery. [34] This result was in contrast to our study in which age hadn't significant relation to ICU survival and renal outcomes. However, the relationship conducted between general characteristics and complications arising from acute kidney injury portrayed significant difference as more age was most presented in acidosis and decreased level of conscious $(29.3 \pm 8 \& 30.4 \pm 8.9$ respectively) compared to those who had no complications their mean age was $26.1 \pm 4.7$. In the same line, several other individual studies have not been able to show that age is specifically associated with impaired renal recovery. [35]

Dragun and Haase [36] who studied Acute kidney failure during pregnancy and postpartum in the later stages, emphasized on frequency of AKI and being associated with preeclampsia, acute fatty liver of pregnancy, hemolytic uremic syndrome (HUS) and sepsis, this study is incongruent to our findings which revealed that $41.2 \%$ of the studied sample had postpartum hemorrhage followed by HELLP syndrome, severe preeclampsia, eclampsia and antepartum hemorrhage with acute fatty liver $(35.3 \%, 14.7 \&$ $8.8 \%$ respectively) as more than half of the sample (56.8\%) were distributed as postpartum cases which emphasized more admission of complicated postpartum cases and make a sound of this preventable cause of AKI. In this respect, Rordorf et al, [37] highlighted that in hospitals, AKI became an important complication when associated with other comorbidities. The identification of risk factors associated with AKI and its poor prognosis is required so that preventive and early diagnosis measures can be taken, aiming to reduce patients' mortality. Our findings were supported by Najar et al. [38] who reported $15 \%$ who had KI was associated with preeclampsia and (12\%) in Ansari et al. [39] While a study of Gurrieri et al. [17] observed that kidney injury was associated with preeclampsia in a substantial percentage $(20.4 \%)$ of patients as well. On the contrary, Hachim et al. [40], Erdemoglu et al. [41] and Arrayhani et al. [31], Said et al, [42] and Suraj et al. [43] found that pre-eclampsia/eclampsia was $(33.3 \%)$. This discrepancy between various studies conducted in different countries might 
be due to good antenatal care leading to decrease incidence of obstetrical and early detection of eclampsia-preeclampsia.

As regards the SOFA scale, the present study revealed that the highest SOFA score $(>16)$ had more significant number of deaths $(60 \%)$ and a significant need cases $(50 \%)$ for renal replacement therapy (RRT) among those who survived and the most significant responsible cause of death among AKI patients was those who had postpartum hemorrhage as 77.8 of them who had high SOFA score compared to other obstetric risk factors. A higher percentage of patients who had postpartum hemorrhage needed RRT, that indicating postpartum hemorrhage considered as the most prevalent relative risk factor for acute kidney injury. However, with medical management for preeclampsia and HEELP syndrome more chance for renal recovery was accomplished. Moreover, the present study found that preeclampsia/ Eclampsia didn't increase risk of AKI complications. Our findings was in agreement with Siam et al [14] findings who reported that, the most common causes of death among cases with AKI were as follows; obstetric hemorrhage $(35 \%)$, HELLP syndrome $(27.5 \%)$, and PIH $(20 \%)$ and incongruent with Said et al, [42] who studied Peripartum Acute Kidney Injury portrayed that the percentage of preeclampsia among AKI group was significantly higher than its percentage among non AKI group (83.7\% versus 67.6\%) respectively. Also, Arora et al [33] reported that the leading causes of pregnancyrelated AKI among the 57 cases studied were sepsis (33.3\%), hemorrhage $(28.1 \%)$ and hypertensive disorders $(26.3 \%)$. Our results revealed that postpartum hemorrhage represented the most significant relative risk factor associated with dialysis (14 women out of 34 had AKI). In this context, the percentage of patients who needed dialysis much less than ours in Hassan et al [44] it was (4\%) Khalil et al [32] was (5\%), Prakash et al [45] was (1\%) and in Arora et al [33] was (3\%) as well. The best results reported in various studies from developed world might be due to good literacy rate, better health care facilities and good antenatal and obstetrical care.

\section{Conclusions}

Based on the findings of the present study, it can be concluded that AKI complicated $10.1 \%$ of total women admitted to the OICU in the studied period and the postpartum hemorrhage represents the most important risk factor for acute kidney injury with greatest SOFA scale $(>16)$ and the most significant responsible cause of their deaths.

\section{Recommendations}

Our findings recommended the followings:

1) Applying SOFA scale for all admitted women to the obstetric ICU to predict early complicated acute kidney injury related pregnancy. (Who, where and when?)

2) Facilitate early nephrology consultation is mandatory to improve maternal and perinatal outcomes as AKI in pregnancy requires a multidisciplinary approach where the nephrologist plays an important role.

3) Workshops should be directed to maternity nurses in $\mathrm{Ob}$ stetric ward \& ICU to increase their awareness toward the impact of ARF on maternal status and fetal well-being.

4) Multi-center prospective studies should be designed to address this potentially important relationship between developed AKI and postpartum hemorrhage. Preventive and therapeutic studies to decrease the incidence and severity of AKI could bring about significant improvements in outcomes of this vulnerable population.

Financial support: This study had no financial support.

\section{Acknowledgement}

We would like to thank all women who participating in this study and the staff nurse at obstetric ICU at Woman Health Hospital, Assiut University Hospital for their valuable participation.

\section{Conflict of interest}

We declare that we have no conflict of interest

\section{Author contributions}

Amal Ismael was responsible for data collection, design, analysis and revision of the manuscript.

Asmaa A was responsible for data collection \& design.

Eman R. was responsible for design, analysis, drafting and revision of the manuscript.

All authors have made essential contributions to this review article as they were all involved in the literature search, evaluation of the literature, writing and editing process. All authors read and approved the final manuscript.

\section{References}

[1] GATT S. (2003) Pregnancy, delivery and the intensive care unit need, outcome and management. Curr. Opin. Anaesthesiol., 16: 263-267, https://doi.org/10.1097/00001503-200306000-00004.

[2] Murugan R, Kellum JA. (2011) acute kidney injury: what's the prognosis? Nat Rev Nephrol; 7:209-17. CrossRef PubMed CAS Web of Science® Times Cited: 105

[3] Coca SG, Singanamala S, Parikh CR. (2012) chronic kidney disease after acute kidney injury: a systematic review and metaanalysis. Kidney Int; 81:442-8. CrossRef | PubMed|Web of Science® Times Cited: 244 https://doi.org/10.1038/ki.2011.379.

[4] Chung $\mathrm{KK}^{1}$, Stewart IJ, Gisler C, Simmons JW, Aden JK, Tilley MA, Cotant CL, White CE, Wolf SE, Renz EM. (2012) The Acute Kidney Injury Network (AKIN) criteria applied in burns. Burn Care Res. 2012 Jul-Aug; 33 (4):483-90 https://doi.org/10.1097/BCR.0b013e31825aea8d.

[5] Turney JH, Ellis CM, Parsons FM. (1989) Obstetric acute renal failure 1956-1987. Br J Obstet Gynaecol; 96:679-87. CrossRefMedlineWeb of Science https://doi.org/10.1111/j.14710528.1989.tb03282.x.

[6] Krane NK. (1988) acute renal failure in pregnancy. Arch Intern Med; 148:2347-57. CrossRefMedlineWeb of Science. https://doi.org/10.1001/archinte.1988.00380110013004.

[7] Stewart GK, Goldstein PJ. (1971) Therapeutic abortion in California. Effects of septic abortion and maternal mortality. Obstet Gynecol; 37:510-4. MedlineWeb of Science

[8] Susana Machado, Nuno Figueiredo, Andreia Borges, Maria São José Pais, Luís Freitas, Paulo Moura, Mário Campos. (2012) Acute kidney injury in pregnancy: a clinical challenge; JNEPHROL; 25(01): 19- 30. https://doi.org/10.5301/jn.5000013.

[9] Rasmussen PE, Nielsen FR. (1988) Hydronephrosis during pregnancy: a literature survey. Eur J Obstet Gynecol Reprod Biol. 1988; 27(3):249-259. https://doi.org/10.1016/0028-2243(88)90130-X.

[10] Krane NK, Hamrahian M. (2007) Pregnancy: kidney diseases and hypertension. Am J Kidney Dis.; 49(2):336-345. https://doi.org/10.1053/j.ajkd.2006.10.029.

[11] Walsh M, Crumbie A. (2007) Caring for the patient with a disorder of the renal and urinary systems. In: Walsh M, Crumbie A (eds.) Watson's Clinical Nursing and Related Sciences. Balliere Tindall Elsevier, Edinburgh: 599-651

[12] Siribamrungwong M, Chinudomwong P. (2016) Relation between acute kidney injury and pregnancy-related factors. Journal of Acute Disease; 5(1); 22-28. https://doi.org/10.1016/j.joad.2015.08.002.

[13] Lewington A, Cerda J, Mehta R. (2013) Raising awareness of acute kidney injury: a global perspective of a silent killer. Kidney International. 2013; 84, 457-467-. https://doi.org/10.1038/ki.2013.153.

[14] Siam S, Abd El-hameed A, Matar H. (2011) Evaluation of Acute Kidney Injury Defined by Rifle Criteria and its Association with Mortality in Critically Ill Obstetric Patients: A Retrospective Study; Med. J. Cairo Univ., Vol. 79, No. 1, December: 589-593. www.medicaljournalofcairouniversity.com 
[15] Nzerue CM, Hewan-Lowe K, Nwawka C. (1998) Acute renal failure in pregnancy: a review of clinical outcomes at an inner-city hospital from 1986-1996. J Natl Med Assoc; 90:486-90.Medline

[16] Turney JH, Marshall DH, Brownjohn AM, Ellis CM, Parsons FM. (1990) the evolution of acute renal failure, 1956-1988. Q J Med.; 74:83-104. [PubMed]

[17] Gurrieri C, Garovic VD, Gullo A, Bojanic K, Sprung J, Narr BJ, (2012) Kidney injury during pregnancy: associated comorbid conditions and outcomes. Arch Gynecol Obstet; 286:567-73. Cross Ref Medline. https://doi.org/10.1007/s00404-012-2323-5.

[18] Bateman BT, Berman MF, Riley LE, Leffert LR. (2010) the epidemiology of postpartum hemorrhage in a large, nationwide sample of deliveries. Anesth Analg; 110:1368-73. CrossRefMedlineWeb of Science https://doi.org/10.1213/ANE.0b013e3181d74898

[19] Murphy F, Byrne G. (2012) The role of the nurse in the management of acute kidney injury, British Journal of Nursing, Vol 19, No 3: 146-52. https://doi.org/10.12968/bjon.2010.19.3.46534.

[20] Andrew JP Lewington, Jorge Cerdá, and Ravindra L Mehta. (2013) Raising Awareness of Acute Kidney Injury: A Global Perspective of a Silent Killer; Kidney Int. 84(3): 457-467. https://doi.org/10.1038/ki.2013.153.

[21] Vincent JL, Moreno R, Takala J, Willatts S, De Mendonça A, Bruining H, Reinhart CK, Suter PM, Thijs LG. (1996) The SOFA (Sepsis-related Organ Failure Assessment) score to describe organ dysfunction/failure. On behalf of the Working Group on SepsisRelated Problems of the European Society of Intensive Care Medicine. Intensive Care Med Jul; 22(7):707-10. PMID 8844239 https://doi.org/10.1007/bf01709751.

[22] Mehta RL, Kellum JA, Shah SV, Molitoris BA, Ronco C, Warnock DG, Levin L. (2007) Acute Kidney Injury Network: report of an initiative to improve outcomes in acute kidney injury. Critical Care; 11(2):1-8. https://doi.org/10.1186/cc5713.

[23] Davison J. (2005) renal complications that may occur in pregnancy: The Oxford Text Book of Clinical Nephrology. $3^{\mathrm{r}}$ ed, Vol. 15. Oxford: Oxford University Press; p. 2233-42.

[24] Hinkle J, Cheever K. (2014) Textbook of Medical-Surgical Nursing. $13^{\text {th }}$ edition: Wolters Kluwer Health/ Lippincott Williams \&Wilkins; 2014. Unit 12. p. 1540

[25] Prakash J, Vohra R, Wani IA, Murthy AS, Srivastva PK, Tripath K, Pandey LK, Usha, and Raja R: (2007) Decreasing incidence of renal cortical necrosis in patients with acute renal failure in $10 \mathrm{de}$ veloping countries: a single-centre experience of 22 years from Eastern India. Nephrol Dial Transplant; 22: 1213-1217. https://doi.org/10.1093/ndt/gfl761.

[26] Goplani KR, Shah PR, Gera DN, Gumber M, Dabhi M, Feroz A, Kanodia K, Suresh S, Vanikar AV, Trivedi HL. (2008) Pregnancyrelated acute renal failure: A single-center experience. Indian $\mathrm{J}$ Nephrol; 18: 17-21. https://doi.org/10.4103/0971-4065.41283.

[27] Ostermann M and Chang R (2008): Riyadh ICU Program Users Group. Correlation between the AKI classification and outcome. Crit Care.12 (6):R144. https://doi.org/10.1186/cc7123.

[28] Godara SM, Kute VB, Trivedi HL, Vanikar AV, Shah PR, Gumber MR, Patel HV, Gumber VM. (2014) Clinical profile and outcome of acute kidney injury related to pregnancy in developing countries: A single-center study from India. Saudi J Kidney Dis Transpl; 25:906-11 https://doi.org/10.4103/1319-2442.135215.

[29] Mandelbaum T, Scott DJ, Lee J, Mark RG, Malhotra A, Waika SS, Howell MD, Talmor D. (2011) Outcome of critically ill patients with acute kidney injury using the Acute Kidney Injury Network criteria. Crit Care Med. 2011 Dec; 39(12):2659-64. https://doi.org/10.1097/ccm.0b013e3182281f1b.

[30] Ashraf Talaat, Elmetwally Elshahawy, Amr M. El Hammady, Mohamed El-Assal, Samir Abdullah. (2014) Epidemiology, clinical characteristics and outcome of acute kidney injury in intensive care units in Egyptian patients, Life Science Journal; 11(7):1-8. http://www.lifesciencesite.com

[31] Arrayhani M, El Youbi R, Sqalli T. (2013) Pregnancy-Related Acute Kidney Injury Volume 2013, Article ID 109034, 5 pages.

[32] Khalil M. A., A. Azhar, N. Anwar, Aminullah, Najmud-Din, and R. Wali, (2009)"Aetiology, maternal and foetal outcome in 60 cases of obstetrical acute renal failure, Journal of Ayub MedicalCollege, vol. 21 , no. 4 , pp. $46-49$

[33] Arora N., K. Mahajan, N. Jana, Taraphder A. (2010) "Pregnancy related acute renal failure in eastern India," International Journal of Gynecology and Obstetrics, vol. 111, no., p. 213-216

[34] Colmant C, Frydman T. R., (2009) "Y a-t-il des grossesses et des accouchements à bas risque?"Gynécologie Obstétrique \& Fertilité, vol. 37, no. $2, \quad$ pp. 195-199. https://doi.org/10.1016/j.gyobfe.2008.12.001.
[35] Schmitt R, Coca S, Kanbay M, Tinetti M, Cantley L, Parikh C. (2008): Recovery of kidney functions after acute kidney injury in the elderly: a systematic review and meta-analysis. Am J Kidney Dis 52: 262-271? https://doi.org/10.1053/j.ajkd.2008.03.005

[36] Dragun K, Haase M. (2010) Acute kidney failure during pregnancy and postpartum. In: Jörres A, Ronco C, Kellum J, eds. Management of acute kidney problems. Springer; Berlin. 2010:445-458. https://doi.org/10.1007/978-3-540-69441-0 45.

[37] Rordorf G, Koroshetz W, Efird JT et al., (2000): Predictors of mortality in stroke patients admitted to an intensive care unit. Crit Care Med May; 28(5):1301-5. https://doi.org/10.1097/00003246200005000-00007.

[38] Najar M. S., A. R. Shah, I. A. Wani, and L. Saldanha, (2008) "Pregnancy related acute kidney injury a single center experience from the Kashmir Valley," Indian Journal of Nephrology, vol. 18, o. 4, pp.159-161. https://doi.org/10.4103/0971-4065.45291.

[39] Ansari M. R., M. S. Laghari, and K. B. Solangi, (2008) "Acute renal failure in pregnancy: one year observational study at Liaquat University Hospital, Hyderabad," Journal of the Pakistan MedicalAssociation, vol. 58, no. 2, pp. 61-64.

[40] Hachim K, Badahi K, Benghanem M, Fatihi EM, Zahiri K. (2001) Obstetrical acute renal failure. Experience of nephrology department, Central University Hospital Ibn Rochd, Casablanca. Nephrologie; 22(1):29-31.

[41] Erdemoðlu M., U. Kuyumcuoðlu, A. Kale, and N. Akdeniz. (2010) "Pregnancy-related acute renal failure in the southeast region of Turkey: analysis of 75 cases,"Clinical and Experimental Obstetrics and Gynecology, vol. 37, no. 2, pp. 148-149.

[42] Khamis S, Emara M, Abdel-Ghani M, Naggar M. (2015) Peripartum Acute Kidney Injury; Nature and Science;13(3):1-10

[43] Godara SM, Kute VB, Trivedi HL, Vanikar AV, Shah PR, Gumber MR, Patel HV, Gumber VM. (2014) Clinical profile and outcome of acute kidney injury related to pregnancy in developing countries: A single-center study from India; Volume: 25(Issue: 4) Page: 906911.

[44] Hassan I, Junejo A.M, Dawani M.L. (2009) Etiology and outcome of acute renal failure in pregnancy; J Coll Physicians Surg Pak, 19 , pp. 714-717

[45] Prakash J, Niwas SS, Parekh A, Pandey LK, Sharatchandra L, Arora P, Mahapatra AK. (2010) acute kidney injuryin late pregnancy in developing countries. Ren Fail; 32(3):309-313. https://doi.org/10.3109/08860221003606265 